\title{
Alzheimer's Disease: The Effect of Nrf2 Signaling Pathway on Cell Death Caused by Oxidative Stress
}

\section{Shahnaz Babaei Abraki ${ }^{1}$, Sara Chavoshi-Nezhad ${ }^{2 *}$}

${ }^{1}$ Shefa Neuroscience Research Center, Khatam Alanbia Hospital, Tehran, Iran.

${ }^{2}$ Departments of Biology, Faculty of Biological Sciences, Kharazmi University, Tehran, Iran.

\section{A BSTRACT}

Introduction: There is an increasing prevalence of Alzheimer's disease (AD). Amyloidbeta deposition and neurotoxicity play an effective role in AD. Oxidative stress is thought to be central in the pathogenesis that leads to production of reactive oxygen species and causing damages of the macromolecules in target cells. It has been reported that the nuclear factor erythroid 2 related factor $2(\mathrm{Nrf} 2)$ is a key regulator of endogenous inducible defense systems in the body and increase the level of many antioxidants, including glutathione-s-transferase. Under oxidative damage conditions, Nrf2 translocates to the nucleus, binds to the antioxidant response element (ARE), and enhances sequence to initiate transcription of cytoprotective genes. This review focuses on cellular mechanisms of $\mathrm{Nrf} 2$ regulation and discusses the relationship between Nrf2 regulation and AD. Conclusion: In general, we suggest that Nrf2-ARE activation is a novel neuroprotective pathway that can be consider as a promising therapeutic strategy for the treatment of neurodegenerative disorders, such as AD.

* Corresponding Author: Sara Chavoshi-Nezhad

E-mail: sara.chavoshinezhad@gmail.com 


\title{
بيمارى آلزايمر: اثر مسير سيخنالينَ Nrf2 روى مرى سلولى ناشى از استرس اكسيداتيو
}

\author{
شهناز بابايى آبراكى'، سارا هاوشى نزاد٪"
}

'مركز تحقيقات علوم اعصاب شفا، بيمارستان خاتم الانبياء، تهران، ايران.

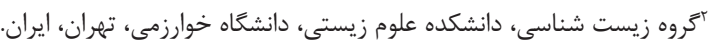

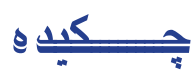

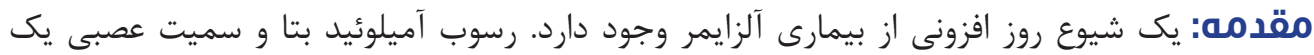

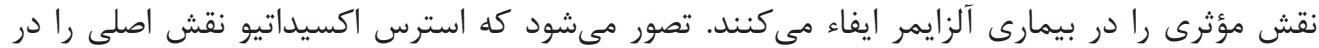

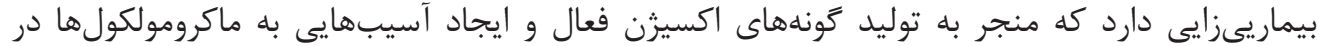

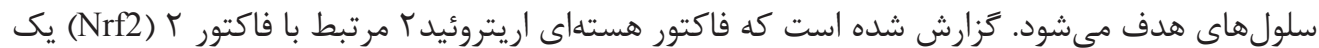

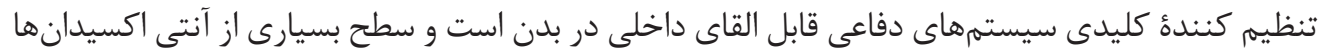

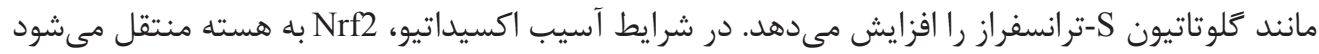

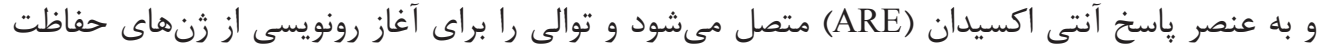

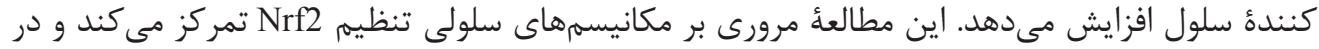

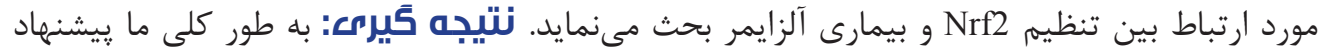

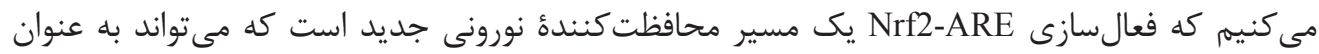

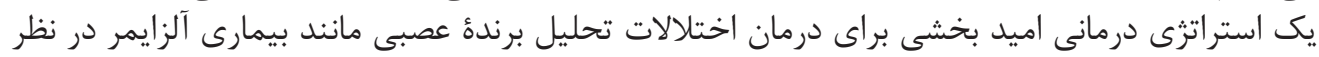
كرفته شود.

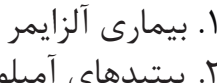

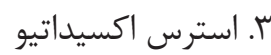

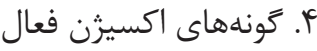

" نويسنده مسئول: سارا هاوشى نزاد آدرس الكترونيكى: sara.chavoshinezhad@gmail.com 


$$
\text { كونهاى اكسيثن فعال و استرس اكسيداتيو }
$$

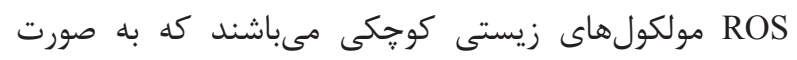

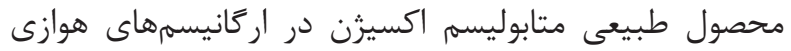

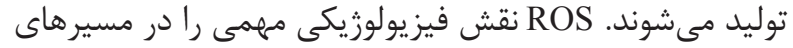

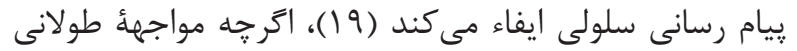

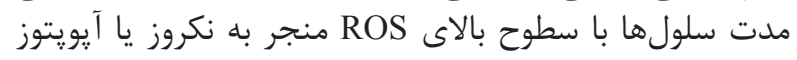

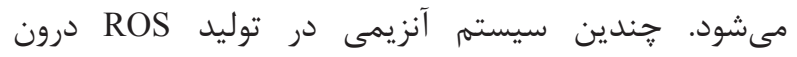

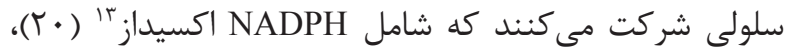

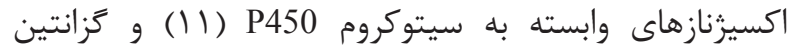

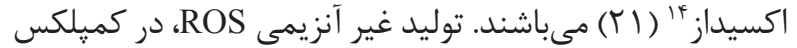

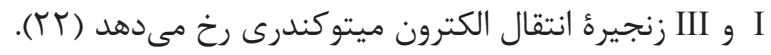

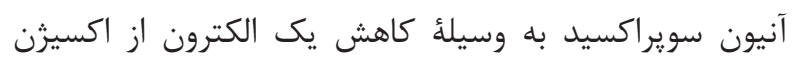

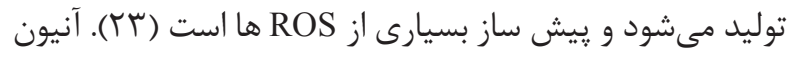

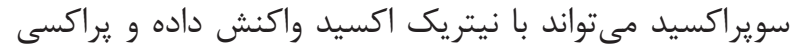

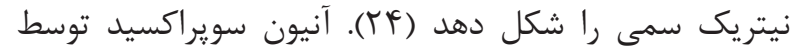

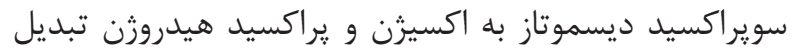

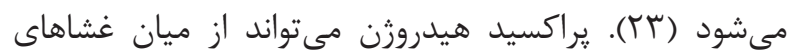

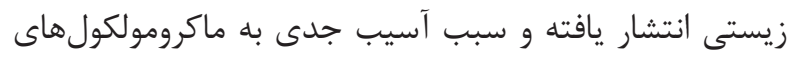

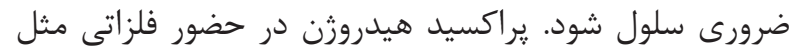

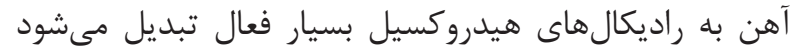

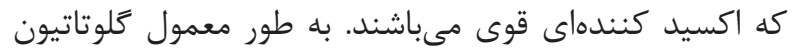

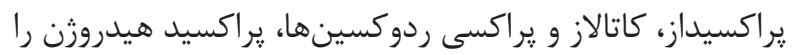

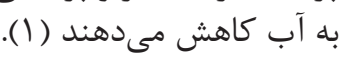

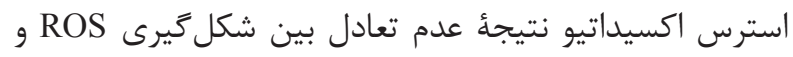

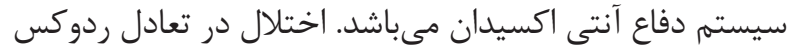

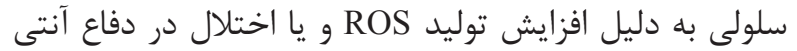

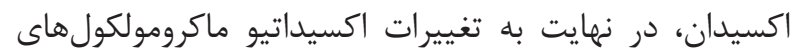

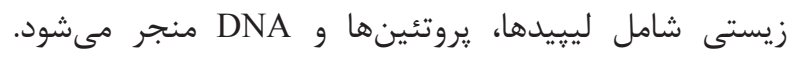

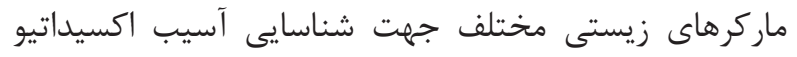

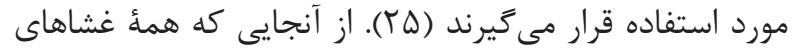

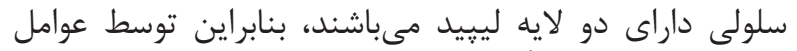

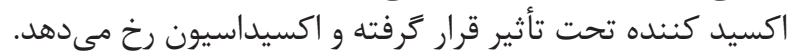

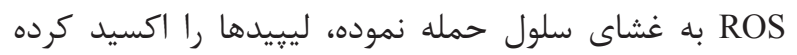

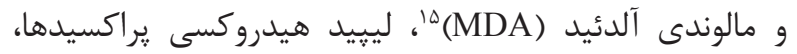

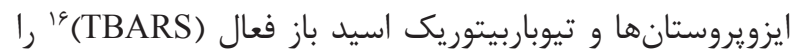

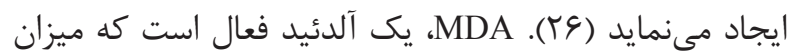

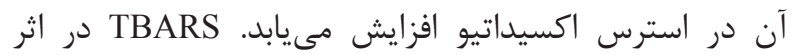

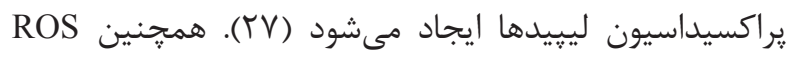

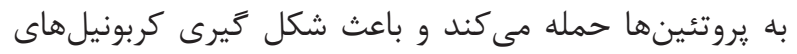

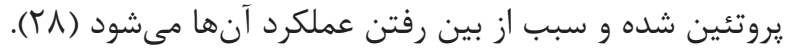

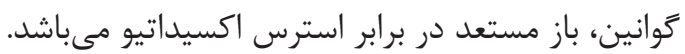

${ }^{1}$ Reactive oxygen species (ROS)

${ }^{2}$ Central nervous system (CNS)

${ }^{3}$ Alzheimer's disease (AD)

${ }^{4}$ Parkinson's disease (PD)

${ }^{5}$ Huntington disease (HD)

${ }^{6}$ Nuclear factor erythroid 2-related factor 2 (Nrf2)

${ }^{7}$ Antioxidant response element (ARE)

${ }^{8}$ Reduction and oxidation (Redox)

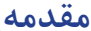

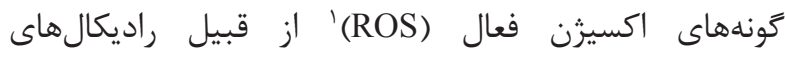

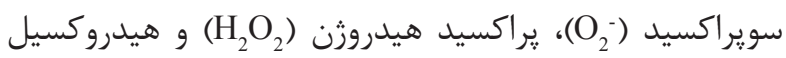

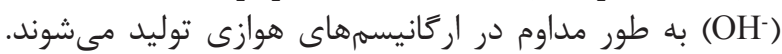

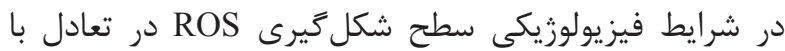

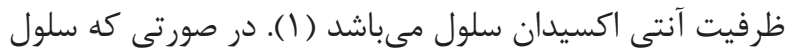

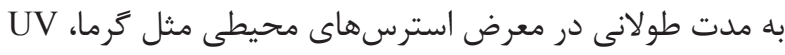

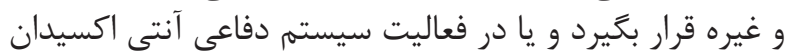

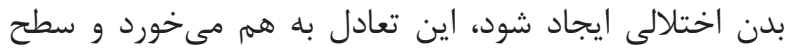

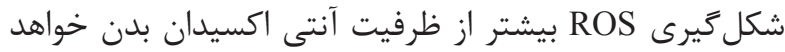

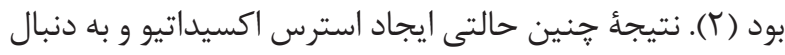

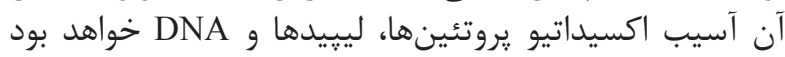

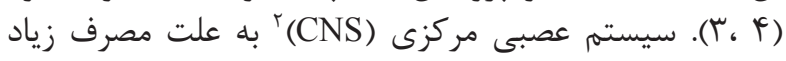

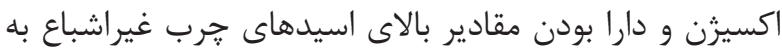
استرس اكسيداتيو حساس مىباشد.

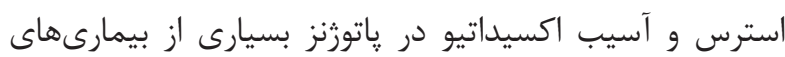

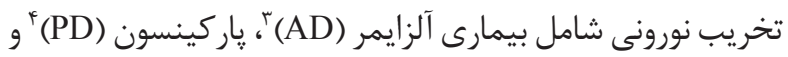

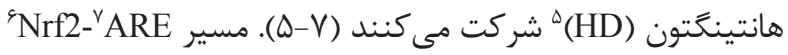

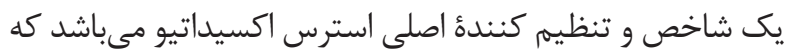

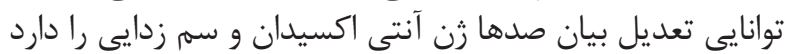

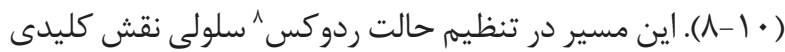

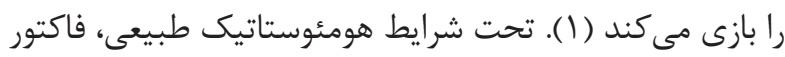

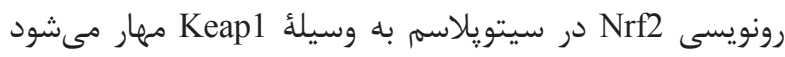
(V، II) Keap1

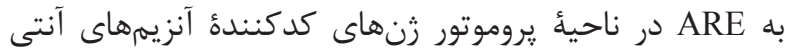

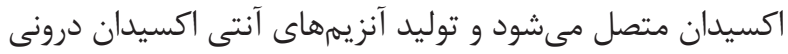

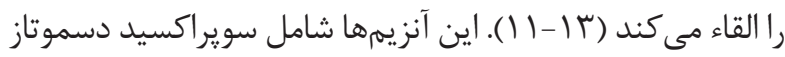
(SOD)

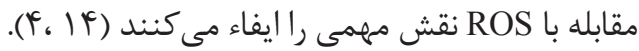

تغييرات ديناميك مسير Nrf2-ARE در بيمارىهاى تخريب

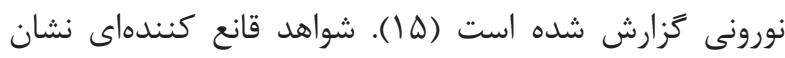

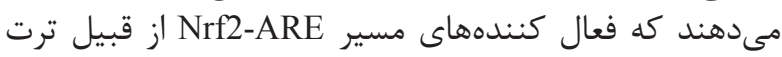

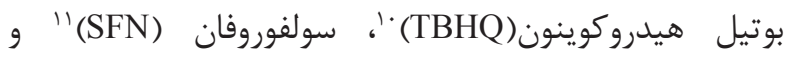

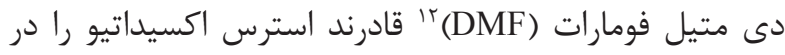

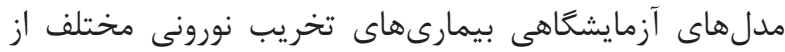

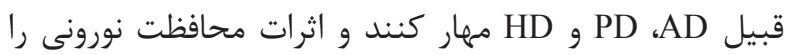

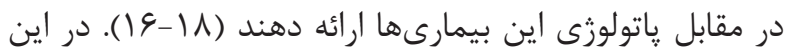

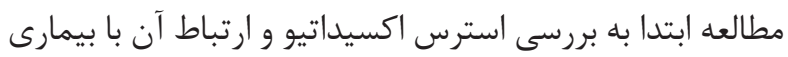

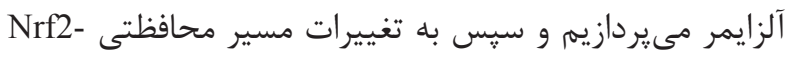
ARE در بيمارى آلزايمر خواهيم يرداخت.

\footnotetext{
${ }^{9}$ Superoxide dismutase (SOD)

${ }^{10}$ Tert-butylhydroquinone (TBHQ)

${ }^{11}$ Sulforaphane (SFN)

${ }^{12}$ Dimethyl Fumarate (DMF)

${ }^{13}$ NADPH oxidase

${ }^{14}$ Xanthine oxidase

${ }^{15}$ Malondialdehyde (MDA)

${ }^{16}$ Thiobarbituric acid reactive substances (TBARS)
} 
Neh3 احتمالاً نقشى را در بايدارى يروتئين Nr2 مبازى مى كند

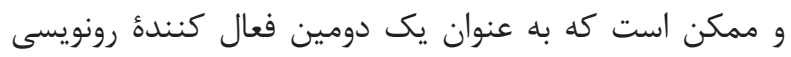

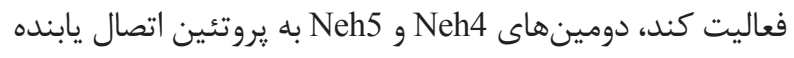

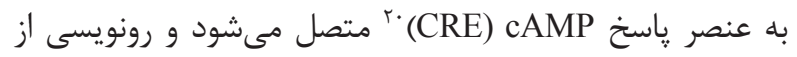

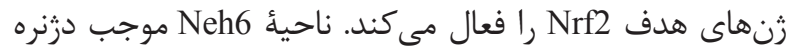

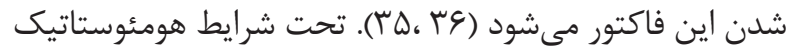

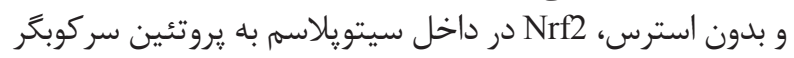

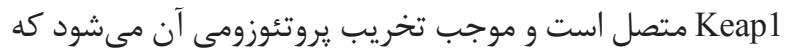

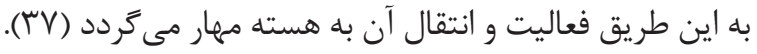
هنگامى كه سلولها در معرض استرس اكسيداتيو و مقادير زياد

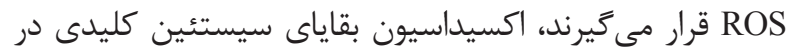

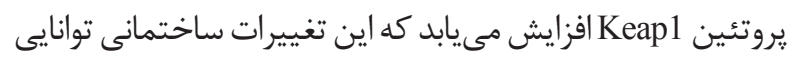

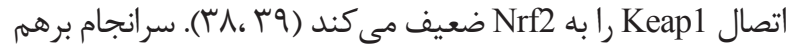

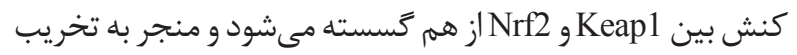

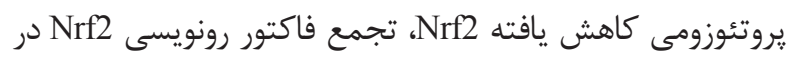

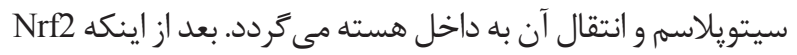

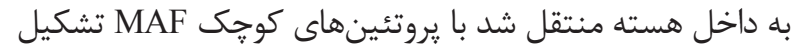

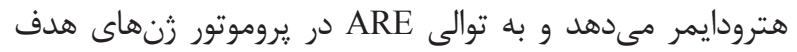

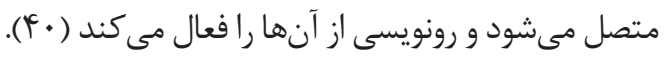
در اين شرايط كه سلول با محصولات اكسيداتيو مقابله

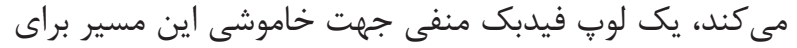

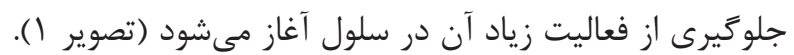

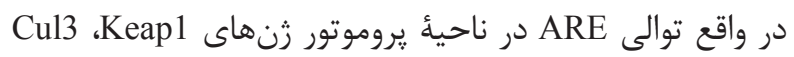

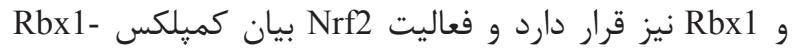

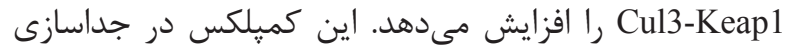

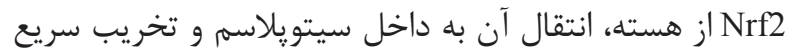

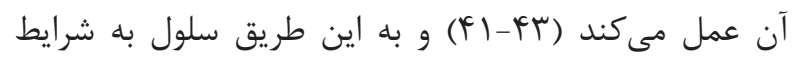

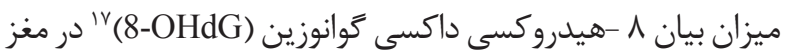
مىتواند براى اندازه گيرى آسيب اكسيداتيو اسيدهاى نوان نوكلئيك

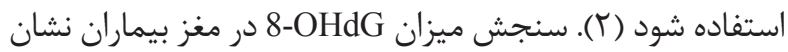

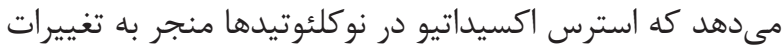

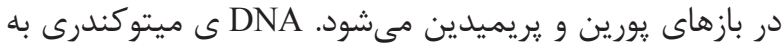

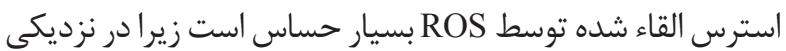

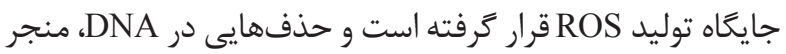

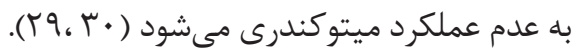

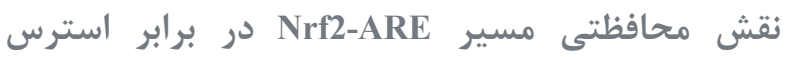
اكسيداتيو

به منظور حفظ تعادل ردوكس، سلولها با تنوعى از آنزيمهاى

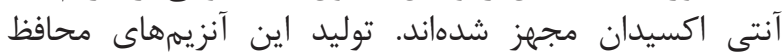

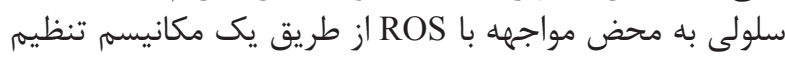

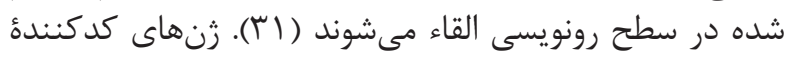

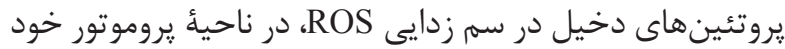

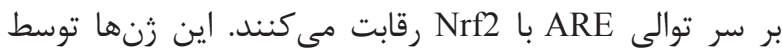

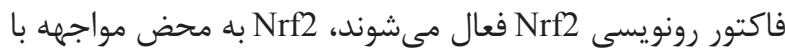

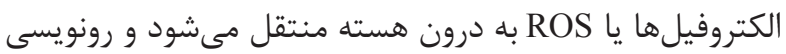

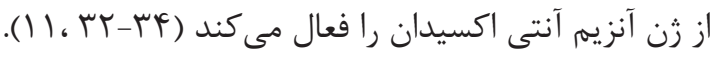

الف. تنظيم مسير Nrf2-ARE

Nrf2

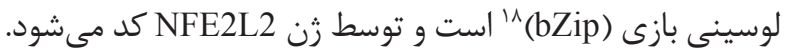
Nrf2

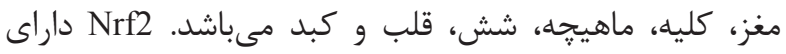

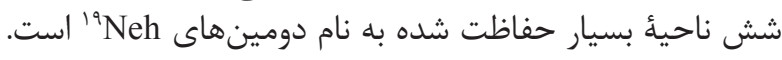

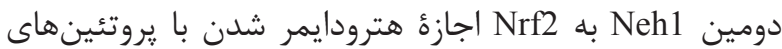

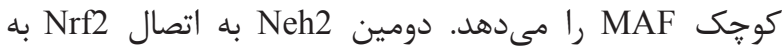

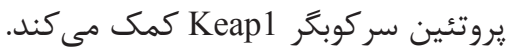

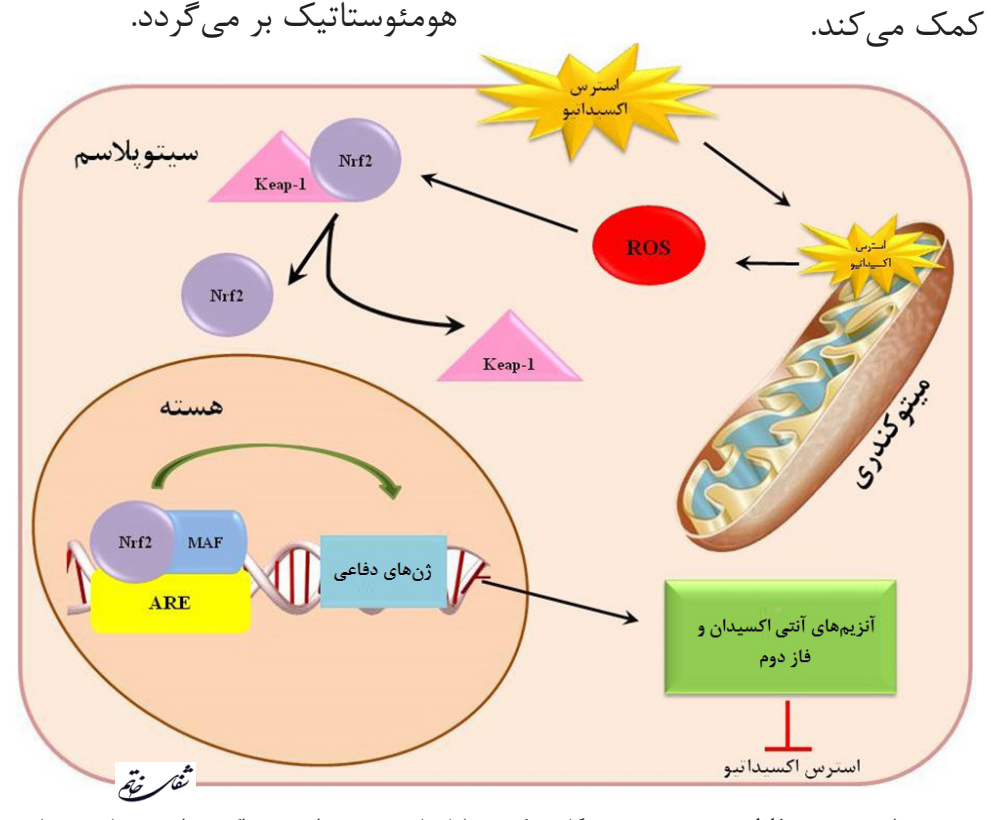

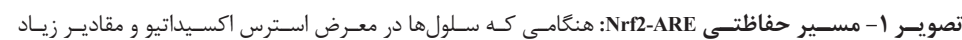

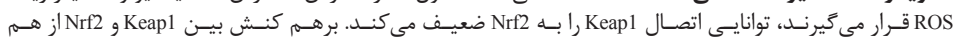

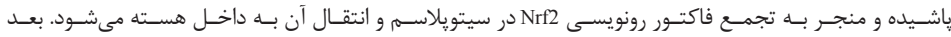

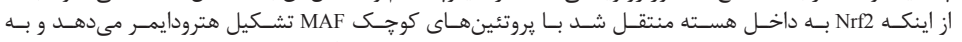

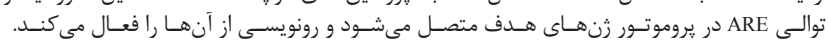

${ }^{17}$ 8-hydroxy-2'-deoxyguanosine (8-OHdG)

${ }^{18}$ Basic-Leucine zipper protein (bZip)
${ }^{19}$ NRF2-ECH homology (Neh)

${ }^{20}$ cAMP response element (CRE) 
شناختى و از دست دادن حافظهُ كوتاه مدت در بيمارى آلزايمر،

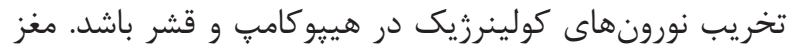
بيماران AD دجار كمبود استيل كولين است (•هرئ (ه).

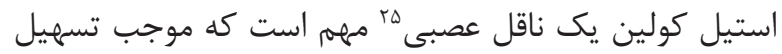

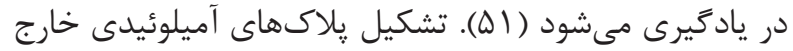

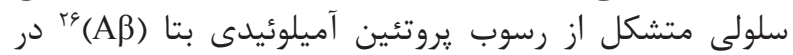

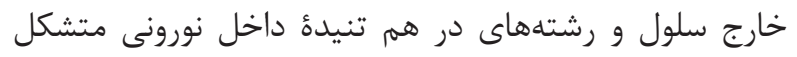

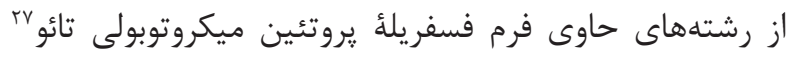

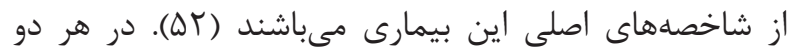

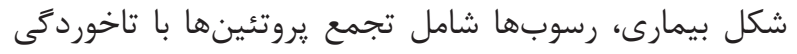

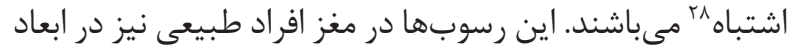

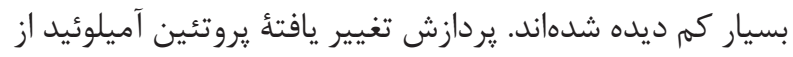

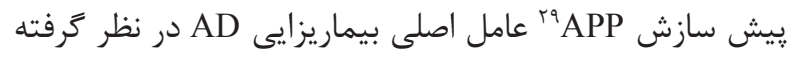

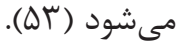

يك يروتئين عرض غشايى با عملكرد ناشناخته است كه در ورو

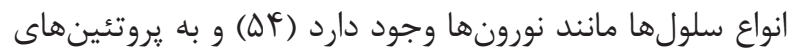

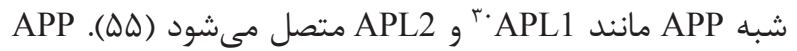

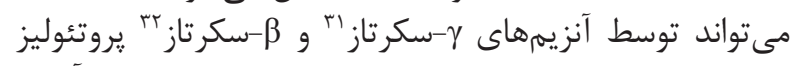

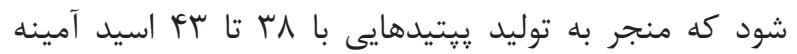

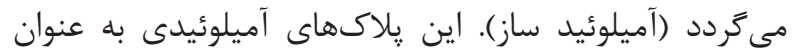

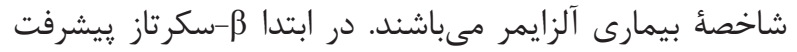

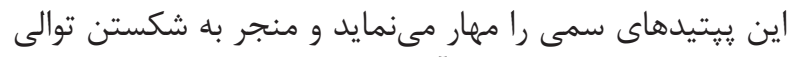

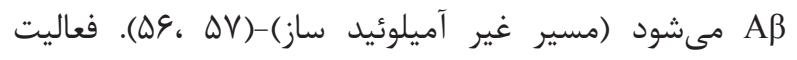

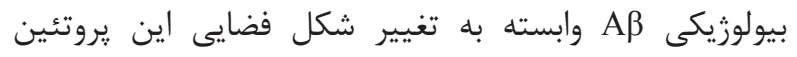

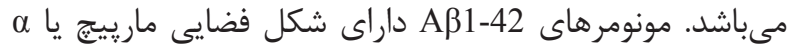

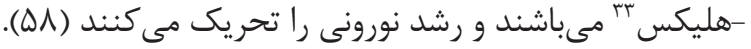

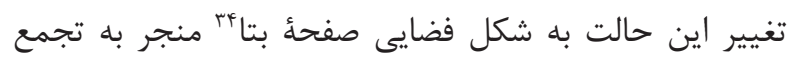

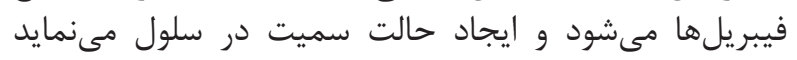

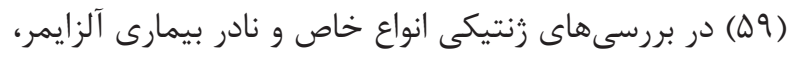

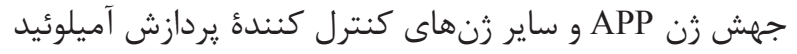

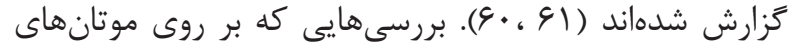

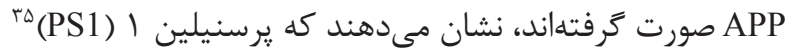

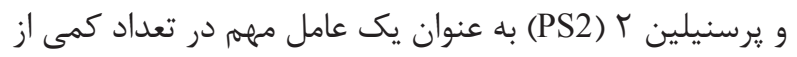

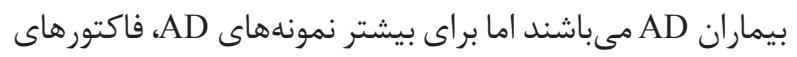

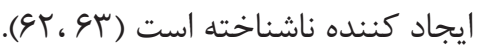

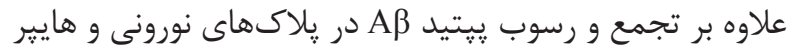

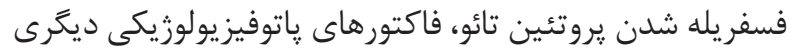

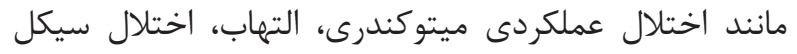

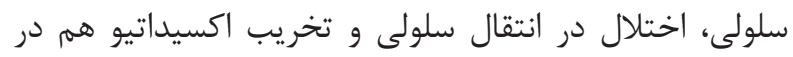

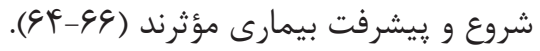

${ }^{21}$ Peroxy redoxine (Prx)

${ }^{22}$ Biliverdin

${ }^{23}$ NADPH: Quinone Oxidoreductase 1 (NQO1)

${ }^{24}$ Glutathione

${ }^{25}$ Neurotransmitter

${ }^{26}$ Amyloid Beta $(\mathrm{A} \beta)$

${ }^{27} \mathrm{Tau}$

${ }^{28}$ Misfolding

\section{ب. هدفهاى پايين دست مسير Nrf2-ARE}

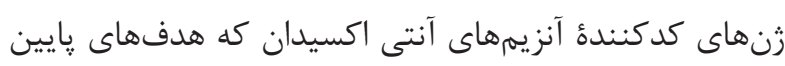
دست اين مسير مىباشند شامل موارد زير هستندي آندان كند

• (1 آنزيم SOD كه در انسان سه فرم از آن شناخته

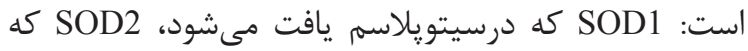

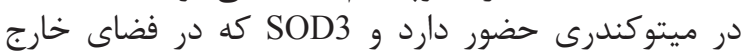

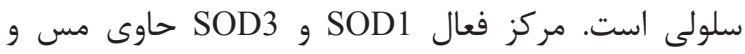

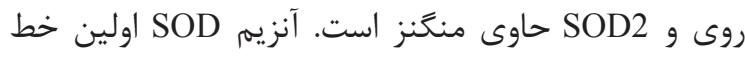

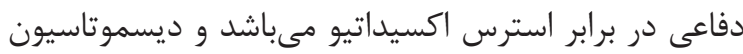

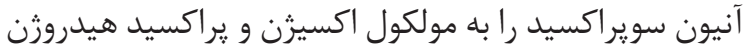

كاتاليز مى كند (1) (1)

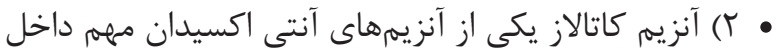

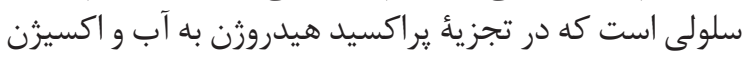

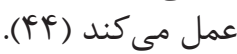

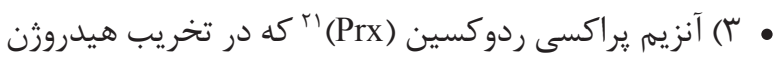

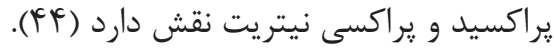

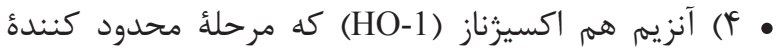

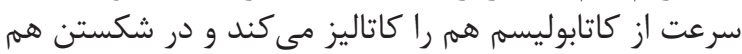

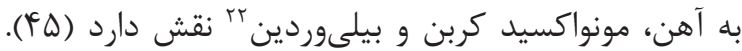

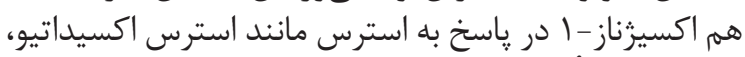

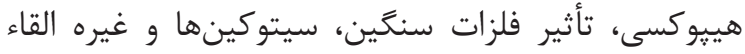

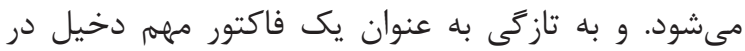

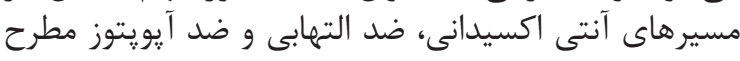

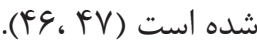

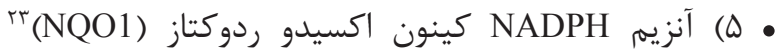

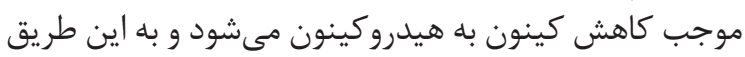

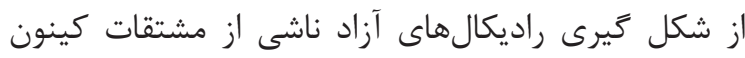

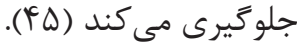

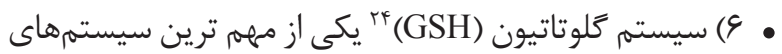

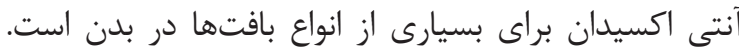
مى GSH

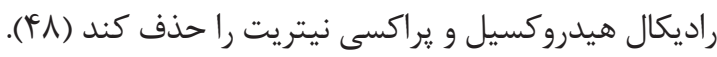
نقش استرس اكسيداتيو در پاتوزنز بيمارى آلزايمر

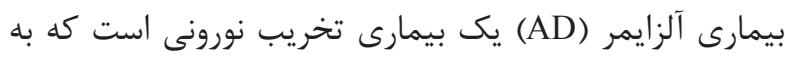

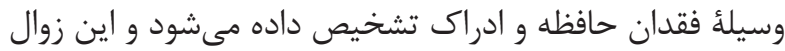

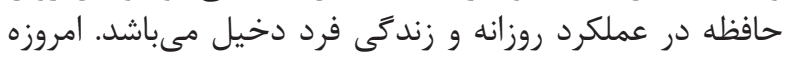

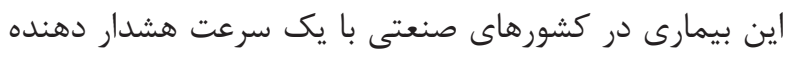

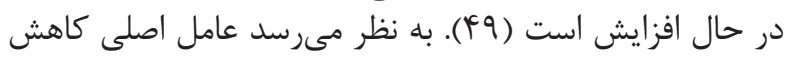

\footnotetext{
${ }^{29}$ Amyloid precursor protein (APP)

${ }^{30}$ Amyloid precursor-like protein (APL)

${ }^{31} \gamma$-Secretase

${ }^{32} \beta$-Secretase

${ }^{33} \alpha$-Helix

${ }^{34} \beta$-Sheet

${ }^{35}$ Presenilin 1
} 
به كاهش سنتز RNA، آسيب اكسيداتيو RNA و در نهايت

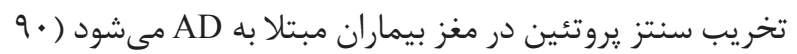

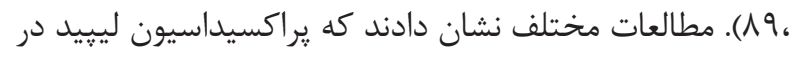

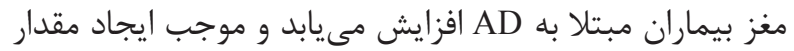

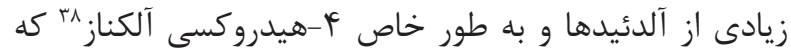

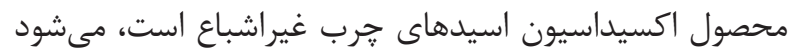

.$(\lambda \cdot 91$. 94$)$

آستروسيتهاى كنش يذير و ميكروخلياهاى فعال شده بال بال

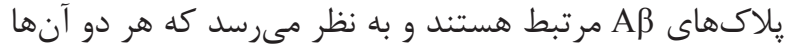

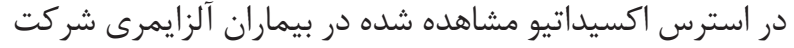

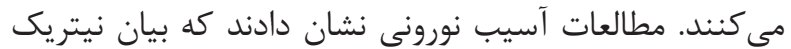

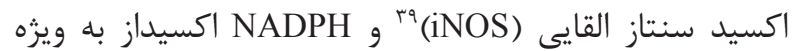

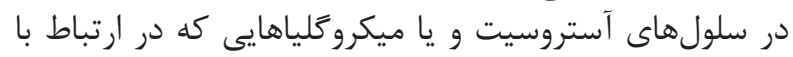

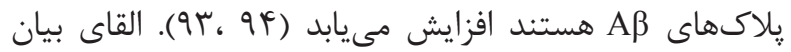

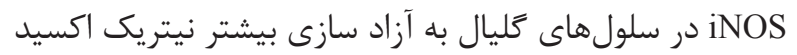

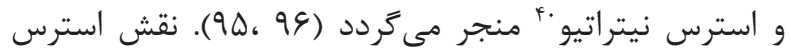

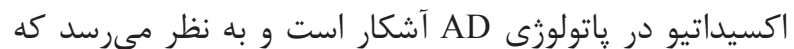

يك رويداد اوليه در تكوين آن است (TI آشكار استو.

در مدلهاى موشى AD، افزايش سطح ماركرهاى استرس

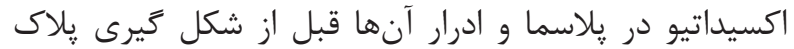

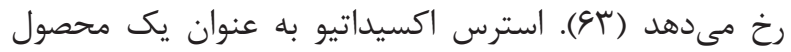

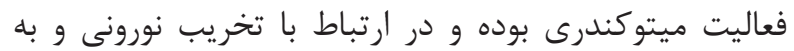

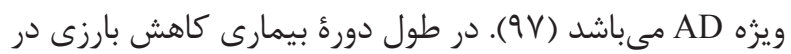

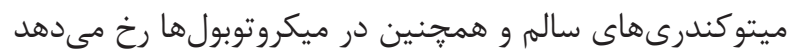

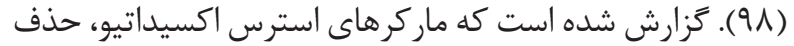
'mtDNA

افراد داراى AD افزايش يافته است (99).

تغيير در آنزيمهاى ميتوكندريايى، ساختار ميتوكندرى، محل

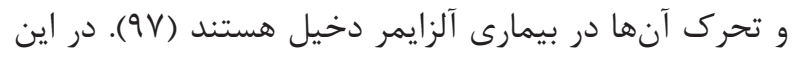

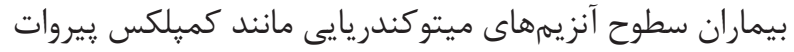

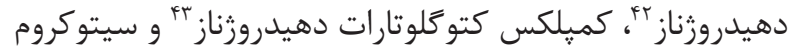

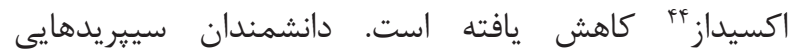

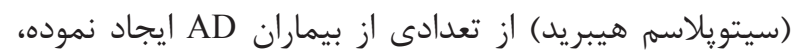

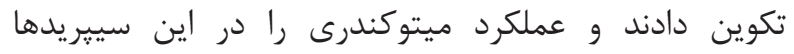

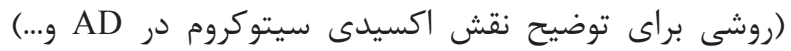

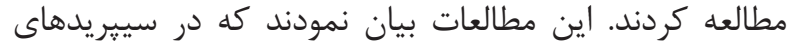

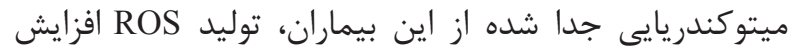

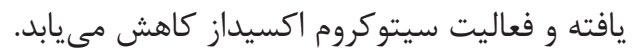

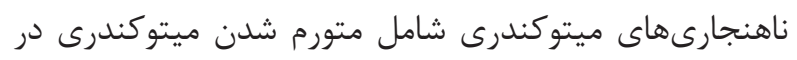

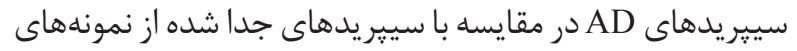

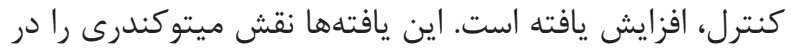

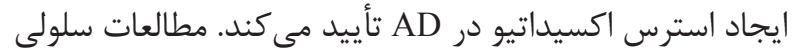
و بيوشيميايى مدلهاى حيوانى تزارش كرداني داند كه موتان

\footnotetext{
${ }^{36}$ Biomarkers

${ }^{37}$ Chaperone

38 4- Hydroxy-alkenals

${ }^{39}$ Inducible nitric oxide synthase (iNOS)

${ }^{40}$ Nitrative stress
}

سيستم عصبى مركزى به دليل مصرف بالاى اكسيثن، غلظت يايين

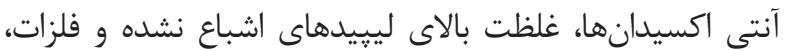

بيشترين حساسيت رانسبت به استرس اكسيداتيو دارد (9 (؟).

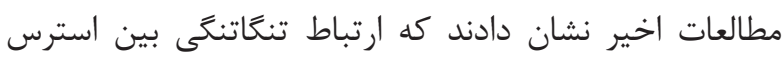

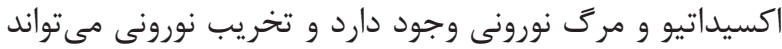

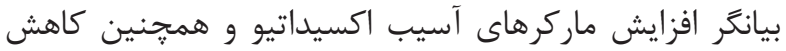

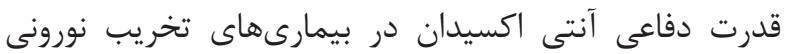

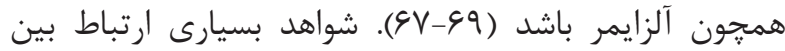

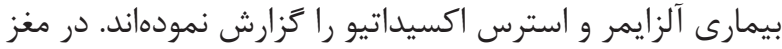

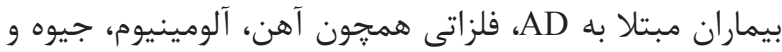

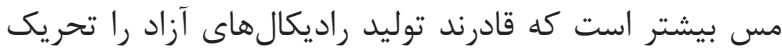

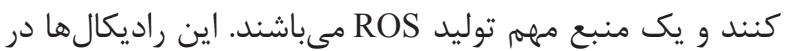

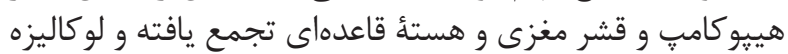

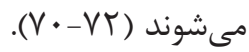

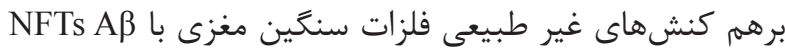

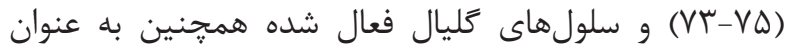

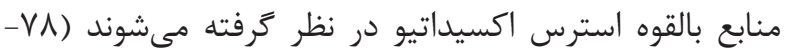

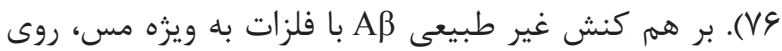

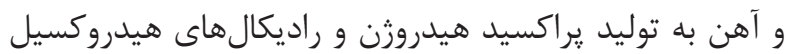

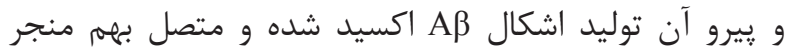

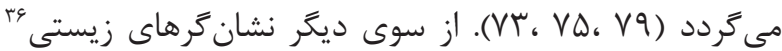

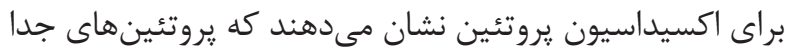

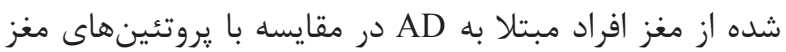

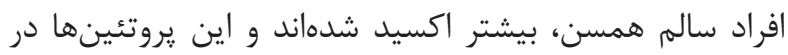

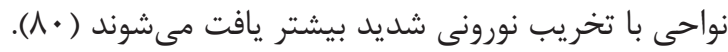

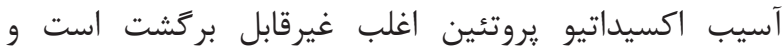

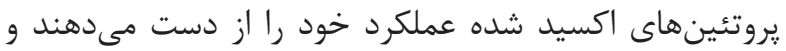

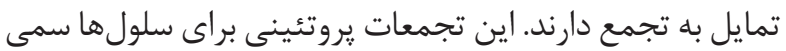

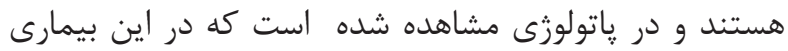

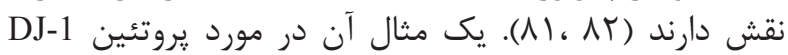

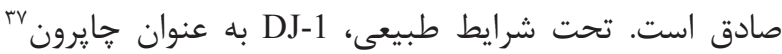

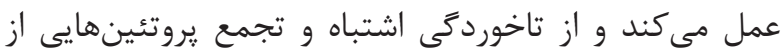

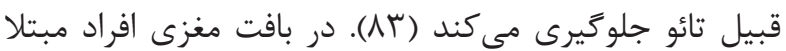

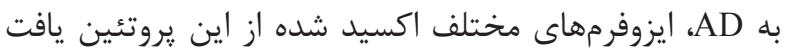

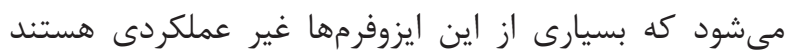

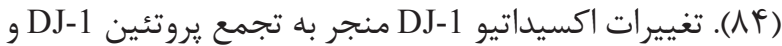

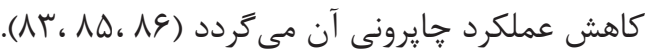

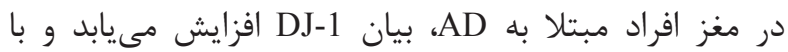

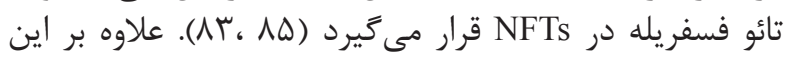

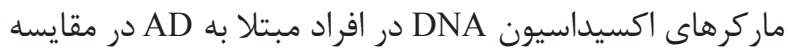

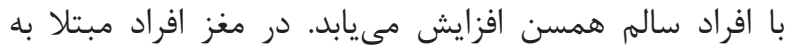

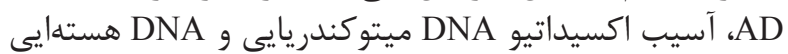
افزايش مى يابد (AV، MN). استرس اكسيداتيو همجنين منجر

\footnotetext{
${ }^{41}$ Mitochondrial DNA or mtDNA

${ }^{42}$ Pyruvate dehydrogenase

${ }^{43}$ Ketoglutarate dehydrogenase complex

${ }^{44}$ Cytochrome oxidase
} 
از آنجا كه يروتئين DJ-1 به طور طبيعى فاكتور Nrf2 را پايدار

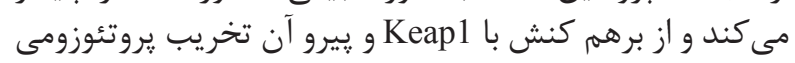

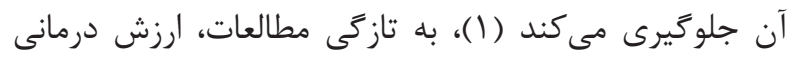

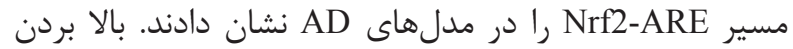

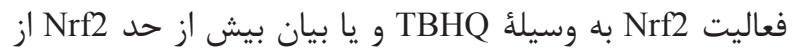

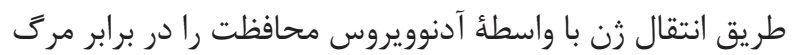

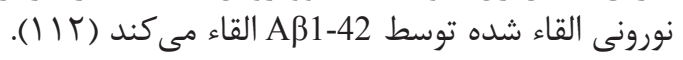

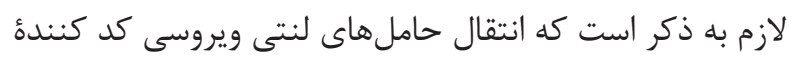

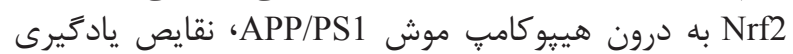

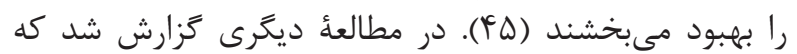

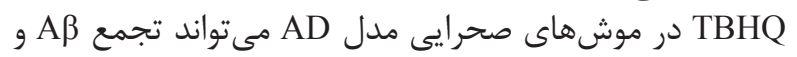

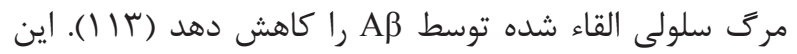

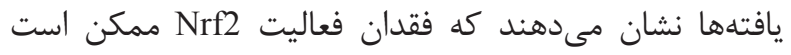

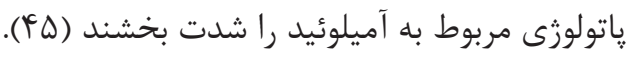

\section{نتيجه كيرى}

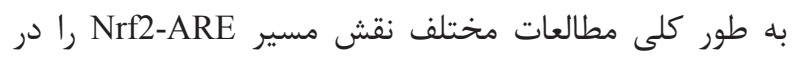

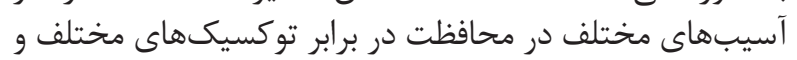

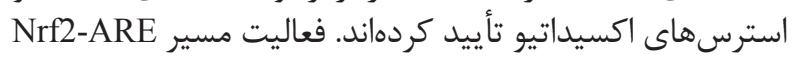

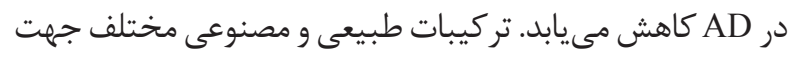

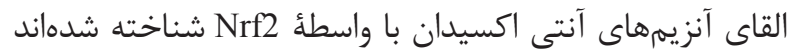

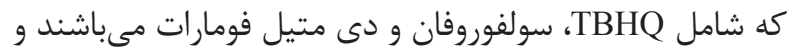

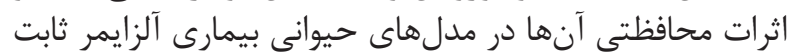

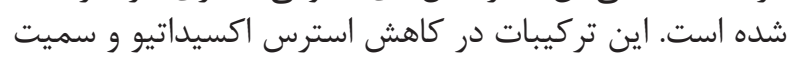
القاء شده توسط A A نقش دارند.

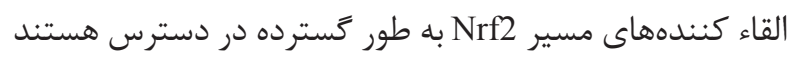

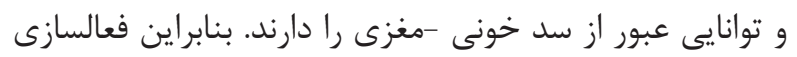

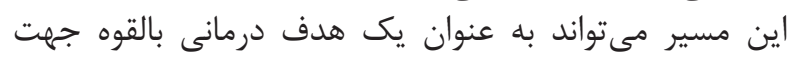

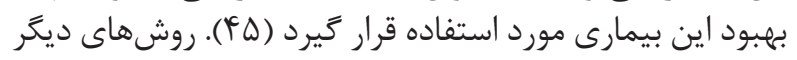

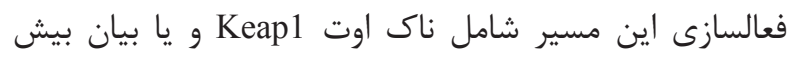

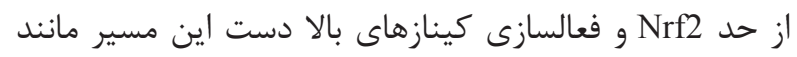

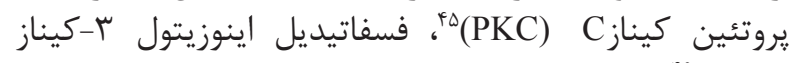
(PI3K)

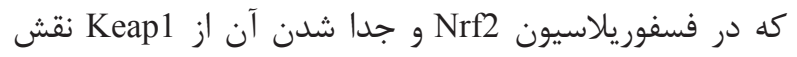

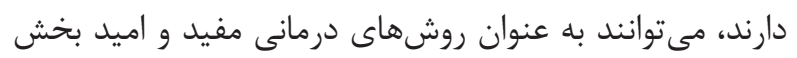

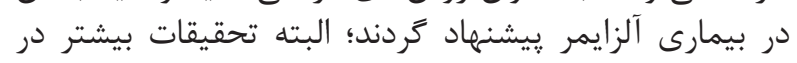

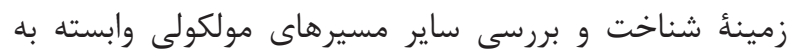

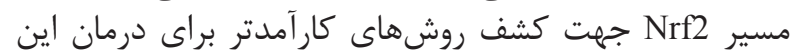

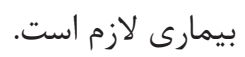

يروتئينهايى شامل PS ها، APP و AB با ميتوكندرى در ارتباط

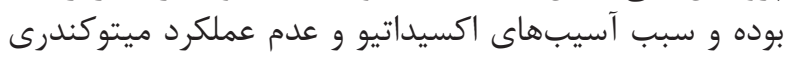

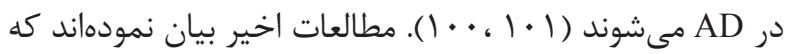

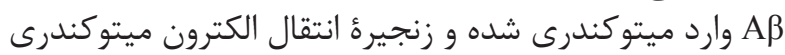

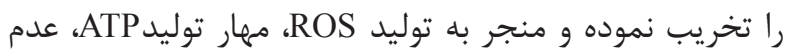

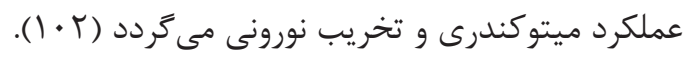
مسير Nrf2-ARE در بيمارى آلزايمر

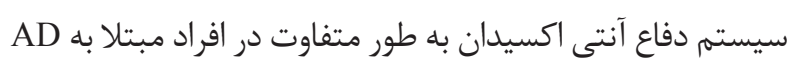

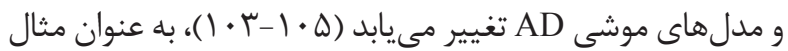

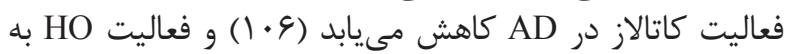

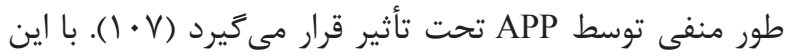

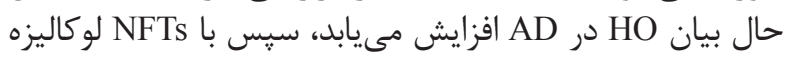

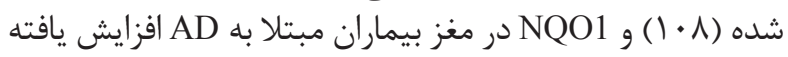

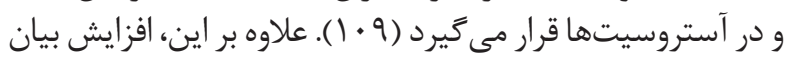

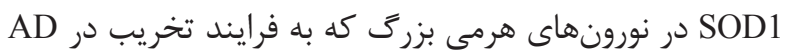

مستعد هستند، مشاهده مى در دمد (·) (1).

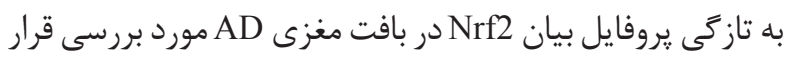

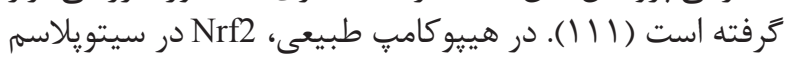

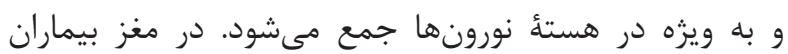

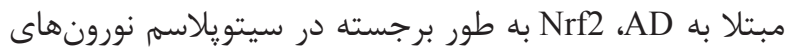

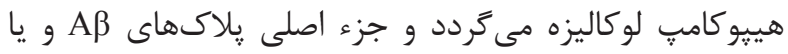
NمFTs

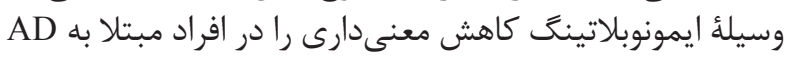

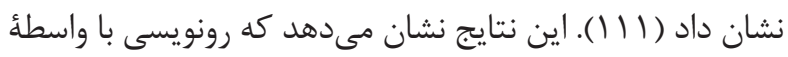
Nrf2 در نورونهاى AD، علىرغم حضور استرس اكسيداتيو

القاء نمىشود (111). (11).

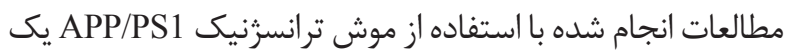

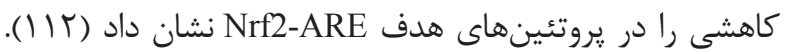

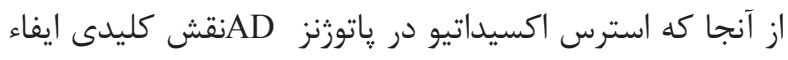

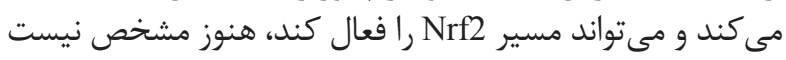

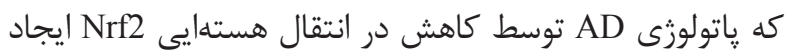

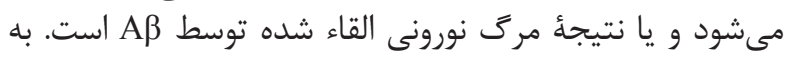

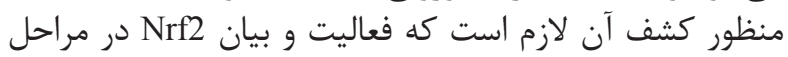

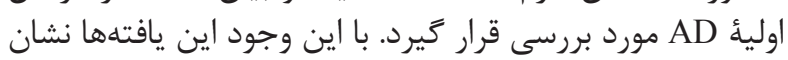

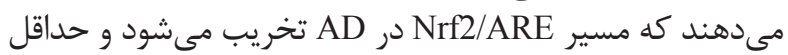

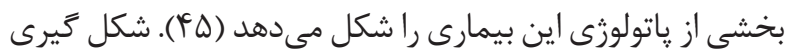

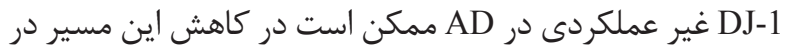
طول بيمارى زايى اين بيمارى نقش دمد داشته باشد.

${ }^{45}$ Protein kinase $\mathrm{C}$

${ }^{46}$ Phosphatidyl inositol 3-kinase 
1. de Vries HE, Witte M, Hondius D, Rozemuller AJ, Drukarch B, Hoozemans J, et al. Nrf2-induced antioxidant protection: a promising target to counteract ROS-mediated damage in neurodegenerative disease? Free Radic Biol Med. 2008; 45(10): 1375-83.

2. Kumar H, Kim IS, More SV, Kim BW, Choi DK. Natural product-derived pharmacological modulators of Nrf2/ARE pathway for chronic diseases. Nat Prod Rep. 2014; 31(1): 109-39.

3. Alaluf S, Muir-Howie H, Hu HL, Evans A, Green MR. Atmospheric oxygen accelerates the induction of a post-mitotic phenotype in human dermal fibroblasts: the key protective role of glutathione. Differentiation. 2000; 66(2-3): 147-55.

4. Ames BN, Shigenaga MK. Oxidants are a major contributor to aging. Ann NY Acad Sci. 1992; 663: 85-96.

5. Johnson JA, Johnson DA, Kraft AD, Calkins MJ, Jakel RJ, Vargas MR, et al. The Nrf2-ARE pathway: an indicator and modulator of oxidative stress in neurodegeneration. Ann N Y Acad Sci. 2008; 1147: 61-9.

6. Lee JM, Calkins MJ, Chan K, Kan YW, Johnson JA. Identification of the NF-E2-related factor-2-dependent genes conferring protection against oxidative stress in primary cortical astrocytes using oligonucleotide microarray analysis. J Biol Chem. 2003; 278(14): 12029-38.

7. Shih AY, Johnson DA, Wong G, Kraft AD, Jiang $\mathrm{L}$, Erb H, et al. Coordinate regulation of glutathione biosynthesis and release by Nrf2-expressing glia potently protects neurons from oxidative stress. J Neurosci. 2003; 23(8): 3394-406.

8. Browne SE, Beal MF. Oxidative damage in Huntington's disease pathogenesis. Antioxidants \& Redox Signaling. 2006; 8(11-12): 2061-73.

9. Jenner P. Oxidative mechanisms in nigral cell death in Parkinson's disease. Mov Disord. 1998; 13 Suppl 1: 24-34.

10. Moreira PI, Siedlak SL, Aliev G, Zhu X, Cash AD, Smith MA, et al. Oxidative stress mechanisms and potential therapeutics in Alzheimer disease. J Neural Transm. 2005; 112(7): 921-32.

11. Bernhardt R. Cytochrome P450: structure, function, and generation of reactive oxygen species. Rev Physiol Biochem Pharmacol. 1996; 127: 137-221.

12. Itoh K, Wakabayashi N, Katoh Y, Ishii T, O'Connor
T, Yamamoto M. Keap1 regulates both cytoplasmicnuclear shuttling and degradation of Nrf2 in response to electrophiles. Genes Cells. 2003; 8(4): 379-91.

13. Nguyen T, Sherratt PJ, Pickett CB. Regulatory mechanisms controlling gene expression mediated by the antioxidant response element. Annu Rev Pharmacol Toxicol. 2003; 43: 233-60.

14. Behl C. Oxidative stress in Alzheimer's disease: implications for prevention and therapy. Subcell Biochem. 2005; 38: 65-78.

15. Gan L, Johnson JA. Oxidative damage and the Nrf2ARE pathway in neurodegenerative diseases. Biochim Biophys Acta. 2014; 1842(8): 1208-18.

16. Chen W, Sun Z, Wang XJ, Jiang T, Huang Z, Fang D, et al. Direct interaction between Nrf2 and p21(Cip1/ WAF1) upregulates the Nrf2-mediated antioxidant response. Mol Cell. 2009; 34(6): 663-73.

17. Eftekharzadeh B, Maghsoudi N, Khodagholi F. Stabilization of transcription factor Nrf2 by tBHQ prevents oxidative stress-induced amyloid beta formation in NT2N neurons. Biochimie. 2010; 92(3): 245-53.

18. Ellrichmann G, Petrasch-Parwez E, Lee DH, Reick C, Arning L, Saft C, et al. Efficacy of fumaric acid esters in the R6/2 and YAC128 models of Huntington's disease. PLoS One. 2011; 6(1): e16172. doi: 10.1371/ journal.pone. 0016172 .

19. Fialkow L, Wang Y, Downey GP. Reactive oxygen and nitrogen species as signaling molecules regulating neutrophil function. Free Radic Biol Med. 2007; 42(2): 153-64.

20. Krause KH. Tissue distribution and putative physiological function of NOX family NADPH oxidases. Jpn J Infect Dis. 2004; 57(5): S28-9.

21. Harrison R. Structure and function of xanthine oxidoreductase: where are we now? Free Radic Biol Med. 2002; 33(6): 774-97.

22. Turrens JF. Mitochondrial formation of reactive oxygen species. J Physiol. 2003; 552(Pt 2): 335-44.

23. Fridovich I. Superoxide radical and superoxide dismutases. Annu Rev Biochem. 1995; 64: 97-112.

24. Pacher P, Beckman JS, Liaudet L. Nitric oxide and peroxynitrite in health and disease. Physiol Rev. 2007; 
87(1): 315-424.

25. Beal MF. Oxidatively modified proteins in aging and disease. Free Radic Biol Med. 2002; 32(9): 797-803.

26. Agil A, Duran R, Barrero F, Morales B, Arauzo M, Alba F, et al. Plasma lipid peroxidation in sporadic Parkinson's disease. Role of the L-dopa. J Neurol Sci. 2006; 240(1-2): 31-6.

27. Bruce AJ, Malfroy B, Baudry M. beta-Amyloid toxicity in organotypic hippocampal cultures: protection by EUK-8, a synthetic catalytic free radical scavenger. Proc Natl Acad Sci U S A. 1996; 93(6): 2312-6.

28. Pradeep AR, Ramchandraprasad MV, Bajaj P, Rao NS, Agarwal E. Protein carbonyl: An oxidative stress marker in gingival crevicular fluid in healthy, gingivitis, and chronic periodontitis subjects. Contemp Clin Dent. 2013; 4(1): 27-31.

29. Halliwell B. Free radicals and antioxidants: updating a personal view. Nutr Rev. 2012; 70(5): 257-65.

30. Wang X, Wang W, Li L, Perry G, Lee HG, Zhu $X$. Oxidative stress and mitochondrial dysfunction in Alzheimer's disease. Biochim Biophys Acta. 2014; 1842(8): 1240-7.

31. Kensler TW, Wakabayashi N, Biswal S. Cell survival responses to environmental stresses via the Keap1-Nrf2ARE pathway. Annu Rev Pharmacol Toxicol. 2007; 47: 89-116.

32. Itoh K, Tong KI, Yamamoto M. Molecular mechanism activating Nrf2-Keap1 pathway in regulation of adaptive response to electrophiles. Free Radic Biol Med. 2004; 36(10): 1208-13.

33. Kobayashi M, Yamamoto M. Nrf2-Keap1 regulation of cellular defense mechanisms against electrophiles and reactive oxygen species. Adv Enzyme Regul. 2006; 46: 113-40.

34. Motohashi H, Yamamoto M. Nrf2-Keap1 defines a physiologically important stress response mechanism. Trends Mol Med. 2004; 10(11): 549-57.

35. Baird L, Dinkova-Kostova AT. The cytoprotective role of the Keap1-Nrf2 pathway. Arch Toxicol. 2011; 85(4): 241-72.

36. Dinkova-Kostova AT, Holtzclaw WD, Wakabayashi N. Keap1, the sensor for electrophiles and oxidants that regulates the phase 2 response, is a zinc metalloprotein. Biochemistry. 2005; 44(18): 6889-99.

37. Stewart D, Killeen E, Naquin R, Alam S, Alam
J. Degradation of transcription factor Nrf2 via the ubiquitin-proteasome pathway and stabilization by cadmium. J Biol Chem. 2003; 278(4): 2396-402.

38. Yuan X, Xu C, Pan Z, Keum YS, Kim JH, Shen G, et al. Butylated hydroxyanisole regulates ARE-mediated gene expression via Nrf2 coupled with ERK and JNK signaling pathway in HepG2 cells. Mol Carcinog. 2006; 45(11): 841-50.

39. Zhang DD, Lo SC, Sun Z, Habib GM, Lieberman MW, Hannink M. Ubiquitination of Keap1, a BTBKelch substrate adaptor protein for Cul3, targets Keap1 for degradation by a proteasome-independent pathway. J Biol Chem. 2005; 280(34): 30091-9.

40. Itoh K, Igarashi K, Hayashi N, Nishizawa M, Yamamoto M. Cloning and characterization of a novel erythroid cell-derived CNC family transcription factor heterodimerizing with the small Maf family proteins. Mol Cell Biol. 1995; 15(8): 4184-93.

41. Kaspar JW, Jaiswal AK. An autoregulatory loop between Nrf2 and Cul3-Rbx1 controls their cellular abundance. J Biol Chem. 2010; 285(28): 21349-58.

42. Lee OH, Jain AK, Papusha V, Jaiswal AK. An autoregulatory loop between stress sensors INrf2 and Nrf2 controls their cellular abundance. J Biol Chem. 2007; 282(50): 36412-20.

43. Sun Z, Zhang S, Chan JY, Zhang DD. Keap1 controls postinduction repression of the Nrf2-mediated antioxidant response by escorting nuclear export of Nrf2. Mol Cell Biol. 2007; 27(18): 6334-49.

44. Rhee SG, Chae HZ, Kim K. Peroxiredoxins: a historical overview and speculative preview of novel mechanisms and emerging concepts in cell signaling. Free Radic Biol Med. 2005; 38(12): 1543-52.

45. Zhang M, An C, Gao Y, Leak RK, Chen J, Zhang F. Emerging roles of Nrf2 and phase II antioxidant enzymes in neuroprotection. Prog Neurobiol. 2013; 100: 30-47.

46. Bauer M, Bauer I. Heme oxygenase-1: redox regulation and role in the hepatic response to oxidative stress. Antioxid Redox Signal. 2002; 4(5): 749-58.

47. Schipper HM, Song W, Zukor H, Hascalovici JR, Zeligman D. Heme oxygenase-1 and neurodegeneration: expanding frontiers of engagement. J Neurochem. 2009; 110(2): 469-85.

48. Aoyama K, Watabe M, Nakaki T. Regulation of neuronal glutathione synthesis. J Pharmacol Sci. 2008; 


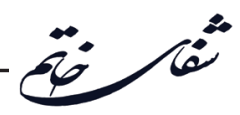

108(3): 227-38.

49. Querfurth HW, LaFerla FM. Alzheimer's disease. N Engl J Med. 2010; 362(4): 329-44.

50. Shanks M, Kivipelto M, Bullock R, Lane R. Cholinesterase inhibition: is there evidence for diseasemodifying effects? Curr Med Res Opin. 2009; 25(10): 2439-46.

51. Chin SP, Buckle MJ, Chalmers DK, Yuriev E, Doughty SW. Toward activated homology models of the human M1 muscarinic acetylcholine receptor. J Mol Graph Model. 2014; 49: 91-8.

52. Grundke-Iqbal I, Iqbal K, Tung YC, Quinlan M, Wisniewski HM, Binder LI. Abnormal phosphorylation of the microtubule-associated protein tau (tau) in Alzheimer cytoskeletal pathology. Proc Natl Acad Sci U S A. 1986; 83(13): 4913-7.

53. Evin G, Weidemann A. Biogenesis and metabolism of Alzheimer's disease Abeta amyloid peptides. Peptides. 2002; 23(7): 1285-97.

54. Lee SH, Kim Y, Kim HY, Kim YH, Kim MS, Kong JY, et al. Aminostyrylbenzofuran directly reduces oligomeric amyloid-beta and reverses cognitive deficits in Alzheimer transgenic mice. PLoS One. 2014; 9(4): e95733. doi: 10.1371/journal.pone.0095733.

55. Blennow K, de Leon MJ, Zetterberg H. Alzheimer's disease. Lancet. 2006; 368(9533): 387-403.

56. Aydin D, Weyer SW, Muller UC. Functions of the APP gene family in the nervous system: insights from mouse models. Exp Brain Res. 2012; 217(3-4): 423-34.

57. Lichtenthaler SF, Haass C, Steiner H. Regulated intramembrane proteolysis--lessons from amyloid precursor protein processing. J Neurochem. 2011; 117(5): 779-96.

58. Zheng H, Koo EH. Biology and pathophysiology of the amyloid precursor protein. Mol Neurodegener. 2011; 6(1): 27. doi: 10.1186/1750-1326-6-27.

59. Goedert M, Spillantini MG. A century of Alzheimer's disease. Science. 2006; 314(5800): 777-81.

60. Hanger DP, Brion JP, Gallo JM, Cairns NJ, Luthert PJ, Anderton BH. Tau in Alzheimer's disease and Down's syndrome is insoluble and abnormally phosphorylated. Biochem J. 1991; 275 (Pt 1): 99-104.

61. Masters CL, Simms G, Weinman NA, Multhaup G, McDonald BL, Beyreuther K. Amyloid plaque core protein in Alzheimer disease and Down syndrome. Proc
Natl Acad Sci U S A. 1985; 82(12): 4245-9.

62. Markesbery WR, Lovell MA. Four-hydroxynonenal, a product of lipid peroxidation, is increased in the brain in Alzheimer's disease. Neurobiol Aging. 1998; 19(1): 33-6.

63. Pratico D, Sung S. Lipid peroxidation and oxidative imbalance: early functional events in Alzheimer's disease. J Alzheimers Dis. 2004; 6(2): 171-5.

64. Kim EJ, Kwon KJ, Park JY, Lee SH, Moon CH, Baik EJ. Effects of peroxisome proliferator-activated receptor agonists on LPS-induced neuronal death in mixed cortical neurons: associated with iNOS and COX-2. Brain Res. 2002; 941(1-2): 1-10.

65. Matsuoka Y, Kitamura Y, Takahashi H, Tooyama I, Kimura H, Gebicke-Haerter PJ, et al. Interferon-gamma plus lipopolysaccharide induction of delayed neuronal apoptosis in rat hippocampus. Neurochem Int. 1999; 34(2): 91-9.

66. Peers C, Dallas ML, Boycott HE, Scragg JL, Pearson HA, Boyle JP. Hypoxia and neurodegeneration. Ann N Y Acad Sci. 2009; 1177: 169-77.

67. Cui K, Luo X, Xu K, Ven Murthy MR. Role of oxidative stress in neurodegeneration: recent developments in assay methods for oxidative stress and nutraceutical antioxidants. Prog Neuropsychopharmacol Biol Psychiatry. 2004; 28(5): 771-99.

68. Konishi T. Brain oxidative stress as basic target of antioxidant traditional oriental medicines. Neurochem Res. 2009; 34(4): 711-6.

69. Limon-Pacheco J, Gonsebatt ME. The role of antioxidants and antioxidant-related enzymes in protective responses to environmentally induced oxidative stress. Mutat Res. 2009; 674(1-2): 137-47.

70. Casadesus G, Smith MA, Zhu X, Aliev G, Cash $\mathrm{AD}$, Honda $\mathrm{K}$, et al. Alzheimer disease: evidence for a central pathogenic role of iron-mediated reactive oxygen species. J Alzheimers Dis. 2004; 6(2): 165-9.

71. Honda K, Casadesus G, Petersen RB, Perry G, Smith MA. Oxidative stress and redox-active iron in Alzheimer's disease. Ann N Y Acad Sci. 2004; 1012: 179-82.

72. Smith MA, Harris PL, Sayre LM, Perry G. Iron accumulation in Alzheimer disease is a source of redoxgenerated free radicals. Proc Natl Acad Sci U S A. 1997; 94(18): 9866-8.

73. Bush AI. The metallobiology of Alzheimer's disease. Trends Neurosci. 2003; 26(4): 207-14. 
74. Doraiswamy PM, Finefrock AE. Metals in our minds: therapeutic implications for neurodegenerative disorders. Lancet Neurol. 2004; 3(7): 431-4.

75. Huang X, Moir RD, Tanzi RE, Bush AI, Rogers JT. Redox-active metals, oxidative stress, and Alzheimer's disease pathology. Ann NYAcad Sci. 2004; 1012: 153-63.

76. Colton CA, Chernyshev ON, Gilbert DL, Vitek MP. Microglial contribution to oxidative stress in Alzheimer's disease. Ann N Y Acad Sci. 2000; 899: 292-307.

77. Colton CA, Gilbert DL. Production of superoxide anions by a CNS macrophage, the microglia. FEBS Lett. 1987; 223(2): 284-8.

78. Eckert A, Keil U, Marques CA, Bonert A, Frey C, Schussel K, et al. Mitochondrial dysfunction, apoptotic cell death, and Alzheimer's disease. Biochem Pharmacol. 2003; 66(8): 1627-34.

79. Head E, Garzon-Rodriguez W, Johnson JK, Lott IT, Cotman CW, Glabe C. Oxidation of Abeta and plaque biogenesis in Alzheimer's disease and Down syndrome. Neurobiol Dis. 2001; 8(5): 792-806.

80. Sultana R, Perluigi M, Butterfield DA. Protein oxidation and lipid peroxidation in brain of subjects with Alzheimer's disease: insights into mechanism of neurodegeneration from redox proteomics. Antioxid Redox Signal. 2006; 8(11-12): 2021-37.

81. Grune T, Jung T, Merker K, Davies KJ. Decreased proteolysis caused by protein aggregates, inclusion bodies, plaques, lipofuscin, ceroid, and 'aggresomes' during oxidative stress, aging, and disease. Int J Biochem Cell Biol. 2004; 36(12): 2519-30.

82. Grune T, Merker K, Sandig G, Davies KJ. Selective degradation of oxidatively modified protein substrates by the proteasome. Biochem Biophys Res Commun. 2003; 305(3): 709-18.

83. Kumaran R, Kingsbury A, Coulter I, Lashley T, Williams D, de Silva R, et al. DJ-1 (PARK7) is associated with $3 \mathrm{R}$ and $4 \mathrm{R}$ tau neuronal and glial inclusions in neurodegenerative disorders. Neurobiol Dis. 2007; 28(1): 122-32.

84. Choi J, Sullards MC, Olzmann JA, Rees HD, Weintraub ST, Bostwick DE, et al. Oxidative damage of DJ-1 is linked to sporadic Parkinson and Alzheimer diseases. J Biol Chem. 2006; 281(16): 10816-24.

85. Rizzu P, Hinkle DA, Zhukareva V, Bonifati V, Severijnen LA, Martinez D, et al. DJ-1 colocalizes with tau inclusions: a link between parkinsonism and dementia. Ann Neurol. 2004; 55(1): 113-8.
86. Zhou W, Zhu M, Wilson MA, Petsko GA, Fink AL. The oxidation state of DJ-1 regulates its chaperone activity toward alpha-synuclein. J Mol Biol. 2006; 356(4): 1036-48.

87. Mecocci P, Mac Garvey U, Beal MF. Oxidative damage to mitochondrial DNA is increased in Alzheimer's disease. Ann Neurol. 1994; 36(5): 747-51.

88. Wang J, Xiong S, Xie C, Markesbery WR, Lovell MA. Increased oxidative damage in nuclear and mitochondrial DNA in Alzheimer's disease. J Neurochem. 2005; 93(4): 953-62.

89. Ding Q, Markesbery WR, Cecarini V, Keller JN. Decreased RNA, and increased RNA oxidation, in ribosomes from early Alzheimer's disease. Neurochem Res. 2006; 31(5): 705-10.

90. Nunomura A, Honda K, Takeda A, Hirai K, Zhu $\mathrm{X}$, Smith MA, et al. Oxidative damage to RNA in neurodegenerative diseases. J Biomed Biotechnol. 2006; 2006(3): 82323 .

91. Lovell MA, Ehmann WD, Mattson MP, Markesbery WR. Elevated 4-hydroxynonenal in ventricular fluid in Alzheimer's disease. Neurobiol Aging. 1997; 18(5): 457-61.

92. Volkel W, Sicilia T, Pahler A, Gsell W, Tatschner T, Jellinger $\mathrm{K}$, et al. Increased brain levels of 4-hydroxy2-nonenal glutathione conjugates in severe Alzheimer's disease. Neurochem Int. 2006; 48(8): 679-86.

93. Lee SC, Dickson DW, Liu W, Brosnan CF. Induction of nitric oxide synthase activity in human astrocytes by interleukin-1 beta and interferon-gamma. J Neuroimmunol. 1993; 46(1-2): 19-24.

94. Shimohama S, Tanino H, Kawakami N, Okamura N, Kodama H, Yamaguchi T, et al. Activation of NADPH oxidase in Alzheimer's disease brains. Biochem Biophys Res Commun. 2000; 273(1): 5-9.

95. Smith MA, Richey Harris PL, Sayre LM, Beckman JS, Perry G. Widespread peroxynitrite-mediated damage in Alzheimer's disease. J Neurosci. 1997; 17(8): 2653-7.

96. Wallace MN, Geddes JG, Farquhar DA, Masson MR. Nitric oxide synthase in reactive astrocytes adjacent to beta-amyloid plaques. Exp Neurol. 1997; 144(2): 266-72.

97. Hirai K, Aliev G, Nunomura A, Fujioka H, Russell RL, Atwood CS, et al. Mitochondrial abnormalities in Alzheimer's disease. J Neurosci. 2001; 21(9): 3017-23.

98. Grivennikova VG, Vinogradov AD. Generation of 


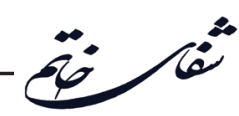

superoxide by the mitochondrial Complex I. Biochim Biophys Acta. 2006; 1757(5-6): 553-61.

99. Manczak M, Anekonda TS, Henson E, Park BS, Quinn J, Reddy PH. Mitochondria are a direct site of A beta accumulation in Alzheimer's disease neurons: implications for free radical generation and oxidative damage in disease progression. Hum Mol Genet. 2006; 15(9): 1437-49.

100. Reddy PH. Mitochondrial medicine for aging and neurodegenerative diseases. Neuromolecular Med. 2008; 10(4): 291-315.

101. Zhang W, Wang PJ, Sha HY, Ni J, Li MH, Gu GJ. Neural stem cell transplants improve cognitive function without altering amyloid pathology in an APP/PS1 double transgenic model of Alzheimer's disease. Mol Neurobiol. 2014; 50(2): 423-37.

102. Rosales-Corral S, Acuna-Castroviejo D, Tan DX, Lopez-Armas G, Cruz-Ramos J, Munoz R, et al. Accumulation of exogenous amyloid-beta peptide in hippocampal mitochondria causes their dysfunction: a protective role for melatonin. Oxid Med Cell Longev. 2012; 2012: 843649. doi: 10.1155/2012/843649.

103. Geremia E, Baratta D, Zafarana S, Giordano R, Pinizzotto MR, La Rosa MG, et al. Antioxidant enzymatic systems in neuronal and glial cell-enriched fractions of rat brain during aging. Neurochem Res. 1990; 15(7):719-23.

104. Marcus DL, Strafaci JA, Freedman ML. Differential neuronal expression of manganese superoxide dismutase in Alzheimer's disease. Med Sci Monit. 2006; 12(1): BR8-14.

105. Marcus DL, Thomas C, Rodriguez C, Simberkoff K, Tsai JS, Strafaci JA, et al. Increased peroxidation and reduced antioxidant enzyme activity in Alzheimer's disease. Exp Neurol. 1998; 150(1): 40-4.
106. Omar RA, Chyan YJ, Andorn AC, Poeggeler B, Robakis NK, Pappolla MA. Increased Expression but Reduced Activity of Antioxidant Enzymes in Alzheimer's Disease. J Alzheimers Dis. 1999; 1(3): 139-45.

107. Takahashi M, Dore S, Ferris CD, Tomita T, Sawa A, Wolosker H, et al. Amyloid precursor proteins inhibit heme oxygenase activity and augment neurotoxicity in Alzheimer's disease. Neuron. 2000; 28(2): 461-73.

108. Calabrese V, Sultana R, Scapagnini G, Guagliano E, Sapienza M, Bella R, et al. Nitrosative stress, cellular stress response, and thiol homeostasis in patients with Alzheimer's disease. Antioxid Redox Signal. 2006; 8(11-12): 1975-86.

109. SantaCruz KS, Yazlovitskaya E, Collins J, Johnson J, De Carli C. Regional NAD(P)H:quinone oxidoreductase activity in Alzheimer's disease. Neurobiol Aging. 2004; 25(1): 63-9.

110. Delacourte A, Defossez A, Ceballos I, Nicole A, Sinet PM. Preferential localization of copper zinc superoxide dismutase in the vulnerable cortical neurons in Alzheimer's disease. Neurosci Lett. 1988; 92(3): 247-53.

111. Ramsey CP, Glass CA, Montgomery MB, Lindl KA, Ritson GP, Chia LA, et al. Expression of Nrf2 in neurodegenerative diseases. J Neuropathol Exp Neurol. 2007; 66(1): 75-85.

112. Kanninen K, Malm TM, Jyrkkanen HK, Goldsteins G, Keksa-Goldsteine V, Tanila H, et al. Nuclear factor erythroid 2-related factor 2 protects against beta amyloid. Mol Cell Neurosci. 2008; 39(3): 302-13.

113. Nouhi F, Tusi SK, Abdi A, Khodagholi F. Dietary supplementation with tBHQ, an Nrf2 stabilizer molecule, confers neuroprotection against apoptosis in amyloid beta-injected rat. Neurochem Res. 2011; 36(5): 870-8. 